\title{
Analysis and Effects of Microplastics in the Agricultural Soils
}

\author{
Doorgha Ragoobur ${ }^{1}$, Geeta Somaroo' \\ ${ }^{1}$ University of Mauritius \\ Reduit, Mauritius \\ doorgha.ragoobur1@umail.uom.ac.mu; g.somaroo@uom.ac.mu
}

\begin{abstract}
Microplastics (MPs) are pertinacious contaminants which are threatening the delicate balance of the ecosystem. Over the years, various studies have reported the presence of MPs in the marine environment through case studies and reviews, but its presence in the agricultural soils is not fully understood. To date, there exists no standardized methodology for sampling, extraction and characterization of MPs in the agricultural soils. This review aims at encapsulating the different techniques used for sampling and extraction of MPs, and includes the methods employed for identification and quantification of MPs in the soil environment. Flotation method, pressurized fluid extraction and elutriation are some of the different techniques used for MPs extraction that usually influence the characterization step. Visual identification through microscope and scanning electron microscope and chemical identification via Fourier-transform infrared (FITR) and Raman spectrometry, are the main techniques that are used for the identification of MPs. The fate and dispersion of MPs in the agricultural soil are discussed, as well as their interaction with the soil biota. The main findings of this review show that further research is needed on the sampling methods as well as analytical techniques so as to contribute to standardizing MPs characterization in the soil environment, potential toxicity effects along the food chain, and global policies for sustainable development.
\end{abstract}

Keywords: Microplastics, Soil, Analytical Method, Terrestrial Environment

\section{Introduction}

Being an indispensable material with a wide range of applications in industrial, domestic and agricultural sectors, plastics are currently posing serious threats to public health and to the environment due to inefficient management of plastic wastes. Since the plastic boom in the 1960s, its demand reached 335 million tonnes in 2016 with an annual increasing rate of $4 \%$ [1]. Plastics have various benefits like durability, strength, malleability, low cost and light-weight [2]. However, they persist in the environment over a long period of time due to their very low degradation rate [3, 4]. Plastic wastes represent about 16 $\%$ of the global municipal solid wastes (MSW) produced and it is estimated that about $10 \%$ of the total plastic ever produced have been released in the marine environment [5]. Plastic wastes enter the oceans through various routes - dumping, wind, rivers and urban water courses - and travel around the world through winds, tides and currents forming gyres [6]. Small pieces of plastic particles were first found floating on the surface of the Sargasso Sea in 1972 [7]. It was not until 2004 that Thompson et al. [8] categorised these plastic particles in terms of their sizes - microplastics (MPs). Any pieces of plastic particles having a particle size less than $5 \mathrm{~mm}$ along its longest dimension are termed as MPs [9]. MPs can be classified into primary and secondary MPs. The primary MPs are plastic particles that have been manufactured intentionally in micro-scale, commonly known as microbeads, and are used in cosmetic and cleaning products, synthetic clothing, toothpaste, and in industrial abrasives $[10,11]$. On the other hand, secondary MPs are a result of the degradation and fragmentation of larger plastics (macroplastics and mesoplastics) due to weathering [3].

MPs have recently become a global concern as they are pertinacious contaminants in the environment and detrimental to the ecosystems $[12,13]$. Several studies have amply stressed on the presence of MPs in the ocean [14]-[17], freshwater [18]-[21], drains [22] and sediments [23]-[26], but limited studies have been conducted in the terrestrial environment [27]. It is estimated that the terrestrial environment is subjected to 4 to 23 times more plastics than the marine environment [3]. Agricultural soil is considered as the preliminary sink of MPs [28] where its presence might be due to the degradation and fragmentation of poorly disposed plastic wastes and plastic films that are used for mulching, road dusts, soil sedimentation, irrigation with treated wastewater, polluted lake water and application of composted sewage sludge [29]-[31]. Plastics are often intentionally left on agricultural lands as it is difficult and time-consuming to remove the thinner plastic film mulching after crop cycle; these films eventually degrade further in MPs [33]. Unfortunately, the detectability and quantification of MPs in the soil environment is challenging and only few studies have reported its occurrence and effects on soil biota [34][37]. Recent reviews have discussed on the behaviour of MPs in the soil [38], toxicological effects, analytical methods [39, 
40] and dispersion in soil [41]. Current research on MPs in the agricultural soils is still at its infancy with various knowledge gaps. Therefore, this paper reviews the current literature on MPs pollution in soil focusing on the analytical methods and effects of MPs on soil biota. The different sampling and extraction techniques, as well as identification and quantification methods that are currently being employed, have been considered. The effects of MPs in the soil ecosystems have also been discussed. Research gaps regarding the analytical methods have been discussed and some perspective for future studies have been proposed.

\section{Sampling Techniques}

Sampling is the first most important step to be carried out for the identification of MPs in any medium [42]. Rillig [43] highlighted that there is a lack of studies on MPs in the soil environment and it has also been found that there are no standardised sampling methodologies and thus, various researchers have come up with different sampling methods for the identification and quantification of MPs in the soil environment $[27,44,45]$. The sampling strategy together with the mass of samples collected govern the amount of MPs extracted [28]. Studies have reported sample collection of mass between $30 \mathrm{~g}$ and $3 \mathrm{~kg}$ and volume between $68 \mathrm{ml}$ and $500 \mathrm{ml}$ from sampling sites [46]-[50]. Nonetheless, given the high heterogeneity of MPs in the soil environment, a single grab sampling may poorly represent the identification and quantification of MPs. Hence, Han et al. [28] affirmed that composite sampling, i.e. taking several discrete samples on the sampling site is more representative than grab sampling. Studies carried out by Zhang and Liu [29] and Lv et al. [37] collected 6 sub-soil samples and three $6 \mathrm{~L}$ sub-soil samples from a plot of $30 \mathrm{~m} \times 5 \mathrm{~m}$ and $667 \mathrm{~m}^{2}$, respectively. However, this significant difference in the amount of sample collected might affect the reliability of the infra study of identification and quantification of MPs. Thus, Han et al. [28] proposed 5 random subsamples for every $1 \mathrm{~m}^{2}$ of land. For more reliable sampling and results, it is recommended that the sample size should be determined statistically. Non-systematic sampling can be employed for agricultural lands where samples are collected along the lines of patterns " $\mathrm{X}$ ", "Y" or "W". Regular grid sampling (systematic sampling) can also be used to determine the direct relationship between the concentration of contamination and the sampling points. Hence, the number of samples collected per $\mathrm{m}^{2}$ can be determined and will be consistent for comparison and standardization. Likewise, the different sampling depths and dimensions need to be considered for an accurate identification of MPs concentration at different soil depths. Shallow or surface layer and deeper layer are often used to describe the different depths of soil sampling (Table 1). As listed in Table 1, the reported depths for shallow and deep sampling differ between $2 \mathrm{~cm}$ and $25 \mathrm{~cm}$, and $3 \mathrm{~cm}$ and $20 \mathrm{~cm}$, respectively. Given the heterogeneity of the soil, the movement of the MPs may vary within the soil, while the different depths of analysis make the comparison challenging. It is also useful to know the previous activities that have been carried out on the sampling sites so as to have better spatial and temporal analysis of the fields. For instance, the frequency of soil tilling, history of sludge and plastic usage on the soil are useful when determining the sampling depth.

Table 1: The sampling methods that are used for different soil types with respect to depth and equipment.

\begin{tabular}{lllc}
\hline Type of soil & Depth $(\mathbf{c m})$ & Equipment & References \\
\hline Beach & Shallow: 2 & Stainless-steel shovel & {$[51]$} \\
Floodplain & Shallow: 5 & Steel tools & {$[34]$} \\
Loess & Shallow: $0-10$ & - & {$[35]$} \\
& Deep: $10-20$ & & {$[52]$} \\
- & Shallow: $0-3$ & & {$[29]$} \\
Nitisol and Gleysol & Deep: -6 & Narrow spade & \\
& Shallow: $0-5$ & & {$[53]$} \\
Loam & Deep: $5-10$ & Metallic soil auger & {$[36]$} \\
Farmland, yellow-brown, & Shallow: $0-25$ & - & {$[28]$} \\
paddy and floodplain & Shallow: $0-6$ & & {$[22]$} \\
- & & Shovel & {$[37]$} \\
Sediment & - & - & Lenz sampler
\end{tabular}




\begin{tabular}{llll} 
& $0-10$ & Soil auger & {$[50]$} \\
Floodplain & $0-30$ & Pile driver & {$[95]$} \\
& $0-50$ & & \\
& $50-150$ & Soil auger & {$[97]$} \\
& $150-200$ & & \\
\hline
\end{tabular}

Note: “-" means Not Reported.

\section{Separation Techniques}

MPs having density ranging from 0.8 to $1.6 \mathrm{~g} / \mathrm{cm}^{3}$, tend to bind to the soil particles, which are of higher density ranging from 2.6 to $2.7 \mathrm{~g} / \mathrm{cm}$, and makes its extraction challenging [13, 45, 54]. Therefore, many studies have come up with various procedures, such as sieving, stirring, ultrasonic treatment and aeration, so as to overcome this issue. Some studies have reported sieving of soil samples through a cascade of sieves of different mesh sizes as the primary step for the MP extraction [55]. For instance, Fuller and Gautam [56] and Scheurer and Bigalke [34] used a sieve size of $1 \mathrm{~mm}$; Zubris and Richards [57] and Corradini et al. [53], used a $2 \mathrm{~mm}$ mesh size, whereas Zhang and Liu [29] used a series of different sieve sizes of $10 \mathrm{~mm}, 2 \mathrm{~mm}, 0.25 \mathrm{~mm}$ and $0.05 \mathrm{~mm}$, for the separation of MPs from the soil.

Density separation or flotation method is the most common and reliable extraction technique that is used for the extraction of MPs [27]. This technique involves the separation of MPs from the soil using different density solution including water, sodium chloride $(\mathrm{NaCl})$, calcium chloride $\left(\mathrm{CaCl}_{2}\right)$, zinc chloride $\left(\mathrm{ZnCl}_{2}\right)$, sodium iodide $(\mathrm{NaI})$ and sodium bromide $(\mathrm{NaBr})$ as shown in Table 2. Extraction using distilled water of density $1.00 \mathrm{~g} / \mathrm{cm}^{3}$ is the most simple and cost effective method as it is harmless as well as readily available [58]. Zhang et al. [35] tested the recovery rate of PP and LDPE MPs from sandy soils, loess soil, pure sand and clay soil using distilled water. The authors mixed soil samples with distilled water manually and treated the mixture to ultrasonic vibration for $2 \mathrm{~h}$, and was then left to settle overnight [35]. The results showed a significant removal of PP and LDPE using distilled water ranged from 80 to $126 \%$ and 86 to $112 \%$, respectively [35]. However, despite the various advantages, MPs cannot be removed due to their higher densities. $\mathrm{NaCl}$ with density of 1.20 $\mathrm{g} / \mathrm{cm}^{3}$ is commonly used for the extraction of MPs, as it is of low-cost, easily available and environment friendly [34]. Thompson et al. [8] reported that $61 \%$ of PE was removed through the first extraction, $83 \%$ through second extraction and $93 \%$ through third extraction using $\mathrm{NaCl}$ only. Liu et al. [52] verified the flotation method using saturated $\mathrm{NaCl}$ and reported a high recovery rate of $90 \%$ for PP, PE, PA, PC and ABS and Polymethyl methacrylate MPs, as shown in Table 2. However, $\mathrm{NaCl}$ is not appropriate for all types of plastics as polyethylene terephthalate (PET) and polyvinyl chloride (PVC) will sink as a result of their higher densities [4]. $\mathrm{CaCl}_{2}$ of density $1.42 \mathrm{~g} / \mathrm{cm}^{3}$ have shown relatively higher extraction of MPs from the soil as shown in Table 2. However, the $\mathrm{CaCl}_{2}$ solution leads to the agglomeration of the organic materials during the separation process [34]. Though $\mathrm{ZnCl}_{2}$ with density $1.55 \mathrm{~g} / \mathrm{cm}^{3}$ has a good extraction efficiency, it is expensive and not environment friendly [4, 21]. NaI having higher density of $1.80 \mathrm{~g} / \mathrm{cm}^{3}$ can extract more MPs from the soil compared with the other previously mentioned floatation solution, unfortunately NaI solution is expensive [58]. NaBr of density $1.55 \mathrm{~g} / \mathrm{cm}^{3}$ has surprisingly showed an extraction efficiency up to $100 \%$ as shown in Table 2.

The extraction analytical time has been reported to take more than 12 hours [27, 59], as shown in Table $\mathbf{2}$. In order to reduce the analytical time, Scheurer and Bigalke [34] highlighted that the centrifugation method decreased the separation process time compared to flotation method only. The flotation method together with centrifugation were also adopted by Liu et al. [60, 36] for sludge samples while Zhang and Liu [29] and Corradini et al. [53] for the extraction of MPs from soil. Moreover, as listed in Table 2, recent studies have shown a combination of different density solutions for the extraction of MPs from soil. For instance, Corradini et al. [53] centrifuged soil samples with distilled water followed by $\mathrm{ZnCl}_{2}$ for maximum extraction of MPs of different densities. Van den Berg et al. [50] adopted a two-step floatation method where soil samples were initially mixed with distilled for $2 \mathrm{~h}$ followed by centrifugation for $10 \mathrm{~min}$ at $3000 \mathrm{RPM}$. The supernatant obtained were filtered while the pellets obtained at the bottom were mixed with $\mathrm{NaI}$ and followed the same procedure as distilled water. Whereas, Han et al. [28] used NaCl-NaI solution mix at a volume ratio of 1:1, aerating for $40 \mathrm{~s}$ for the extraction of MPs and reported an extraction efficiency of $90 \%$. Although density separation is widely practised, MPs below $10 \mu \mathrm{m}$ cannot be separated with this method [58], and the analytical time is still long. 
Moreover, Han et al. [28] highlighted that the mass of the samples and the floatation solution can influence the extraction of MPs and adapted the air-induced overflow method which was proposed by Nuelle et al. [48]. Fuller and Gautam [56] used Pressurized Fluid Extraction (PFE) technique for the separation of MPs (HDPE, PP, PVC, PS and PET) from the soil. A 2-step extraction procedure was developed where the organic compounds were first removed using methanol at $100^{\circ} \mathrm{C}$ followed by the second extraction where dichloromethane was used for the extraction of MPs at $180^{\circ} \mathrm{C}$ and a pressure of 1500 PSI. The authors reported that PFE technique required only 15 minutes to separate the MPs from the samples compared with flotation method only, which would take 2 hours for the separation [56]. This technique has demonstrated the extraction of MP of size less than $30 \mu \mathrm{m}$. Furthermore, elutriation is another emerging technique for MP extraction [27]. Elutriation is the process where the different MP sizes and densities are separated by passing a gas or liquid in the opposite direction of the sample [61]. For instance, Mahon et al. [62] used the elutriation technique to remove MPs from sewage sludge and more than $90 \%$ of HDPE and $80 \%$ of PVC MPs were successfully extracted using $\mathrm{ZnCl}_{2}$ solution. Dikareva and Simon [22] adopted an amalgamation of elutriation technique and flotation method where tap water and $\mathrm{NaI}$ solvent were used, respectively. Felsing et al. [63] effectively demonstrated separation of MPs from different media- freshwater sediment and beach sand with a very high extraction of $99 \%$ using electrostatic behavior. So far, electrostatic techniques has not yet been considered for MP separation from the soil environment.

Besides, there are risks of sample contamination through air-borne plastic particles that might be present in the laboratory and that can also emanate from polyester laboratory coats. Therefore, it is imperative to observe good laboratory housekeeping during analysis [64] so as to obtain reliable extraction results for the identification of MPs in different media. Thus, extracted MPs were often covered using aluminum boxes or foils by studies conducted by the following authors: Zhang et al. [35]; Zhang and Liu [29]; Corradini et al. [53]. In this review, it has been found that very few researchers have conducted validation of extraction and ensured proper laboratory control. Most literature adopted the flotation method with different or combination of floatation solution so as to improve the extraction method. The mass of the sample, floatation solution, mixing time, replicates, settling time, as well as the digestion time influence the rate of extraction. Hence, it is of utmost importance to optimize and standardize the extraction method so as to enhance the comparability of data.

Table 2: Extraction technique and percentage extraction of microplastics in the soil environment.

\begin{tabular}{|c|c|c|c|c|c|}
\hline Floatation Solution & $\begin{array}{l}\text { Mixing time } \\
(\mathrm{min})\end{array}$ & $\begin{array}{l}\text { Settling time } \\
\text { (h) }\end{array}$ & Digestion & $\begin{array}{c}\text { Percentage } \\
\text { Extraction } \\
(\%)\end{array}$ & References \\
\hline Distilled water & - & 24 & $\mathrm{NC}$ & 90 & {$[35]$} \\
\hline $\mathrm{NaCl}$ and $\mathrm{CaCl}_{2}$ & 10 & 48 & $\begin{array}{l}13 \% \\
\mathrm{NaOH}, \quad 96 \% \\
65 \% \\
\mathrm{HNO}_{3} \text {, and } 30 \% \mathrm{H}_{2} \mathrm{H}_{2} .\end{array}$ & 96 & [34] \\
\hline $\mathrm{NaCl}$ & 30 & 24 & $30 \% \mathrm{H}_{2} \mathrm{O}_{2}$ & 90 & {$[52]$} \\
\hline $\begin{array}{l}\text { Distilled water, } \mathrm{NaCl} \\
\text { and } \mathrm{ZnCl}_{2}\end{array}$ & 16 & - & - & 80 & {$[53]$} \\
\hline Distilled water & 5 & - & $\begin{array}{c}\mathrm{H}_{2} \mathrm{O}_{2}, \\
\mathrm{NaOH}, \mathrm{NaI}\end{array}$ & 72 & [29] \\
\hline $\mathrm{NaBr}$ & 5 & 2 & $\mathrm{H}_{2} \mathrm{O}_{2}$ & $85-100$ & {$[36]$} \\
\hline $\mathrm{NaCl}$ & 30 & 24 & $\mathrm{H}_{2} \mathrm{O}_{2}$ & No data & [37] \\
\hline $\begin{array}{l}\text { Methanol, Hexane, } \\
\text { Dichloromethane }\end{array}$ & $\mathrm{NC}$ & $\mathrm{NC}$ & $\mathrm{NC}$ & - & [56] \\
\hline $\begin{array}{l}\text { Tap water and } \mathrm{NaCl}- \\
\mathrm{NaI}\end{array}$ & 0.67 & 0.08 & $35 \% \mathrm{H}_{2} \mathrm{O}_{2}$ & 90 & {$[28]$} \\
\hline $\mathrm{NaCl}$ & 30 & 12 & $\mathrm{NC}$ & & [59] \\
\hline $\begin{array}{l}\text { Distilled water } \\
\text { NaI }\end{array}$ & 120 & $\mathrm{NC}$ & - & - & {$[50]$} \\
\hline
\end{tabular}

Note: "-" mean "Not Reported"; "NC" mean "Not Conducted" 


\section{Digestion}

After the flotation method, some organic matter (SOM) are still present in the extracted MPs samples. The presence of of SOM pose a challenge for the chemical identification of MPs due to binding of soil particles with MPs and the autofluorescence of soil particles can falsify the end result [54, 65]. Therefore, SOM removal is a necessity which can be conducted through acid, alkali or oxidative digestions [4, 54]. $\mathrm{HNO}_{3}, \mathrm{HCL}, \mathrm{H}_{2} \mathrm{SO}_{4}$ are usually used for acid digestion. However, acid digestion resulted in the dissolution and degradation of some polymers, such as, nylon, PS, PE and PET [13, $[13,66,67]$. Scheurer and Bigalke [34] showed that $\mathrm{HNO}_{3}$ removed most $\mathrm{SOM}$ in a short time; but altered the morphology morphology of some MPs like acrylonitrile butadiene styrene (ABS), polyamide (PA) and PET. NaOH and $\mathrm{KOH}$ are common bases which are used in alkali digestion with high SOM removal potential [13] but the increasing molarity of the bases may damage some polymers like PET and PVC [67]. Mintenig et al. [68] treated sewage sludge samples with $\mathrm{NaOH}$ followed by $\mathrm{HCl}$ for neutralization before the flotation technique. Moreover, Cole et al. [14] reported effective digestion through ultrasonication bath with $5 \mathrm{M} \mathrm{NaOH}$ digestive treatment. Hydrogen peroxide $\left(\mathrm{H}_{2} \mathrm{O}_{2}\right)$ is the most efficient oxidizing agent to remove SOM with minimal or no dissolution and degradation of the polymers [13]. Hurley et al. [69] reported that $\mathrm{H}_{2} \mathrm{O}_{2}$ removed up to $87 \%$ and $108 \%$ of organic matter at $70{ }^{\circ} \mathrm{C}$ in sludge and soil respectively without affecting the MPs. As it can be seen, the methodology for the digestion of SOM is diverse which can make comparison of MPs inaccurate.

\section{Characterisation of Microplastics \\ 5.1. Visual Identification}

The most appropriate and simplest method for MP identification is visual identification. This technique classifies MPs based on their physical characteristics such as size (based on the longest dimension), shape (fiber, fragment, bead, foam and film) and colour (using stereoscope microscope) [4]. The most common types of equipment used for visual identification include, stereo, optical, polarized light, trinocular and binocular and FTIR microscopes, as well as scanning electron microscope (SEM) $[29,34,58,56]$. SEM also identifies MPs by providing a high topographical, morphological and compositional image of MPs, as well as, the size of MPs [4]. Eriksen et al. [70] reported that $20 \%$ of particles initially identified as MPs $(<1 \mathrm{~mm})$ by visual identification were misclassified and these $20 \%$ of particles were subsequently identified as aluminum silicate through SEM analysis. However, SEM is relatively expensive and this technique requires a lot of time for sample preparation and identification [4]. The colour of the MPs can be an indicator of the presence of heavy metal in the sample to be analysed. For instance, Massos and Turner [71] reported the presence of cadmium and lead in red and yellow MPs, respectively that were collected from beach sediment samples. Visual identification has undeniably become the primary step for MPs identification as per literature. The colour, shape and the size of the MPs can only be classified using visual sorting. The main constraints associated with visual identification involve misclassification of MPs with other non-plastic materials [13]. Prata et al. [13] also reported that black plastic fragments can be confounded with biological material leading to overestimation or underestimation of white fragments. However, studies have also reported the urge for further analysis of MPs identification using chemical identification techniques.

\subsection{Chemical Identification}

Vibrational techniques like Fourier transform infrared spectroscopy (FTIR), micro( $\mu$ )-FTIR, attenuated total reflectance (ATR)-FTIR, Raman spectrometry and micro( $\mu$ )-Raman spectrometry are the main analytical techniques for MPs characterization [72]. Vibrational spectrometry techniques are non-destructive and highly accurate [13] as the vibrational fingerprint is unique for each polymer [73]. Furthermore, Renner et al. [73] highlighted the importance of data preprocessing workflow for MP identification based on spectroscopy measurement in order to avoid various disturbances. Scheurer and Bigalke [34] showed that FTIR in transition mode was most suitable for MPs of less than $1 \mathrm{~mm}$ in soil samples. Mintenig et al. [68] recommended $\mu$-FTIR over ATR-FTIR for the analysis of sludge samples with high load of synthetic fibers. Whereas, Araujo et al. [74] highlighted the importance of using $\mu$-Raman spectrometry due to high resolution to detect very small MPs. $\mu$-Raman spectrometry can detect MP sizes as low as $1 \mu \mathrm{m}$ compared with $\mu$-FTIR which can detect MPs sizes higher than $10-20 \mu \mathrm{m}$ [4]. However, the high laser energy can as well melt the MPs resulting in poor spectra quality [34]. The

main drawback using vibrational spectrometry is the long process time [4]. Besides, identification of fibers using FTIR has been reported to be challenging $[36,75]$. 


\subsection{Emerging Methods}

Nowadays, there are emerging analytical methods which omit the extraction and digestion steps and can directly MPs from the soil samples. Visible near-infrared (vis-NIR) spectrometer is a technique that is being used to detect MP concentration in different matrices. Corradini et al. [27] predicted the MP concentration in soil with an accuracy of $10 \mathrm{~g}$ $\mathrm{kg}$ with a detection limit of approximately $15 \mathrm{~g}$ per $\mathrm{kg}$. However, this method can only be utilized for highly MPs contaminated medium such as sewage sludge [27]. Thermal extraction desorption gas chromatography spectrometry GC-MS) and pyrolysis gas chromatography mass spectrometry (Pyr-GC-MS) are other analytical techniques that are for MPs characterization [42, 76, 77, 78]. TED-GC-MS is the fastest identification method for PE, PP and PS in complex environment like soil and digestate in anaerobic digestion systems but requires further quantification [42, 79]. Pyr-GCidentification technique has also been reported to be very promising in detecting MPs in fish samples [77, 78]. However, Pyr-GC-MS has not yet been considered for heterogeneous environmental matrices such as soil and sewage sludge. Besides, Shan et al. [59] demonstrated that hyperspectral imaging techniques combined with image processing and chemometric methods can be used to identify MP between 0.5 to $5 \mathrm{~mm}$ from the soil directly.

\section{Quantification of microplastics}

MPs were found to be abundant in agricultural soils, which use plastic mulching and plastic greenhouses [29, 35, 52]. Zubris and Richards [57] and Corradini et al [53] showed that $0.58-1.21$ fibers/g and $18-41$ particles/g, respectively were present in agricultural soils. Agricultural soils with plastic mulching in the Northwest of China were sampled by Zhang et al. [35] and a total amount of approximately $0.54 \mathrm{mg} / \mathrm{kg}$ of PE and PP MPs were found with sizes more than $100 \mu \mathrm{m}$ [35]. Liu et al. [52] investigated the presence of MPs in agricultural soils in the estuary farmlands of Shanghai, China and the results showed that 78 items $/ \mathrm{kg}$ and 62 items $/ \mathrm{kg}$ of MPs were found in shallow and deep soils, respectively. $49 \%$ and $60 \%$ of the total MPs found were less than $1 \mathrm{~mm}$ in shallow and deep soil, respectively. The soil of Chai river valley in China were studied by Zhang and Liu [29] and demonstrated that the concentration of plastic particles ranged between 7,100 to 42,960 particles/kg out of which $95 \%$ were small MPs of sizes ranged between 0.05 to $1 \mathrm{~mm}$ [29]. The study also reported that $92 \%$ were fiber MPs which were the most dominant types followed by $8 \%$ fragments MPs. Zhou et al. [51] investigated MP pollution along the coastal beach soils in China and the results showed that MP abundance varied from 1.3 to $14,712.5 / \mathrm{kg}$. $60 \%$ of the total MP extracted were less than $1 \mathrm{~mm}$ and the types of MPs found were foams $(28 \%)$, pellets $(0.1 \%)$, fragments $(1.1 \%)$, flakes $(69 \%)$, fibers $(1 \%)$, films $(0.2 \%)$ and sponges $(0.8 \%)$ [51]. Scheurer and Bigalke [34] collected soil samples from floodplains in Switzerland and reported an abundance of 593 particles $/ \mathrm{kg}$ of MPs out of which more than $80 \%$ were PE MPs of sizes ranged between 125 to 500 $\mu \mathrm{m}$. Moreover, Corradini et al. [53] sampled sandy loam soil and extracted the MPs from the soil as reported in Table 1 and 2. The results showed that MPs were in the range of 2.3 to $19 \mathrm{MP}$ particles/ $5 \mathrm{~g}$ in the depths of 0 to $25 \mathrm{~cm}$ and out of which $92 \%$ were synthetic fibers [53]. Dikareva and Simon [22] collected soil sediments from small streams in the largest city of New Zealand. The authors reported 80 items of MPs/ kg in the range of 63 to $500 \mu \mathrm{m}$ and out of which yellow films of poly(hexadecyl) methacrylate and black fragments of ethylene/ethyl acrylate copolymer were in abundance [22]. Han et al. [28] collected soil samples on the Jinnan University campus and reported an abundance of 95 MP fragments / kg of dry matter of PP. Liu et al. [80] analysed 4 different types of soil (farmland soil, yellow brown soil, paddy soil and floodplain soil) in China and reported the highest amount of MPs of 256 items $/ \mathrm{kg}$ in the floodplain soils followed by paddy soil with an abundance of 190 items $/ \mathrm{kg}$. The size of MPs ranges between $30 \mu \mathrm{m}$ to $476 \mu \mathrm{m}$ and the microfibers and particles were the salient MPs found in the soils [80]. Lv et al. [37] investigated the MP distribution in 3 rice-fish culture systems and showed an average abundance of 10.3 items $/ \mathrm{kg}$ from the paddy soils. The majority of the MPs found were in the range of $20 \mu \mathrm{m}$ to $1 \mathrm{~mm}$ of PE and PP fibers with white colour and translucent [37]. Ven de Berg et al. [50] studied the distribution of MPs in the agricultural soils with and without the application of sewage sludge. The results showed that the average load of light density MPs and heavy density MPs increased by $280 \mathrm{MPs} / \mathrm{kg}$ and $430 \mathrm{MPs} / \mathrm{kg}$, respectively [50]. Literature shows that the counting of MPs is mostly used for quantification and are reported as items, particles and percentages. MPs particle counts and percentages are not informative enough to represent the total weight of MPs in a particular location. Moreover, reporting in particles number, percentages and weight do not allow comparisons between studies. 


\section{Effect of microplastics on soil ecosystems}

Being omnipresent as a solid pollutant, MPs could affect the soil fundamental properties [58]. For instance, Liu et al. al. [60] showed that the addition of MPs in the loess soil increased the content of dissolved organic as well as activated the the pools of organic C, N and P and stimulated the enzymatic activity [60]. However, de Souza Machado et al. [81] showed showed that different polymer type of MPs had different effects in the soil properties. The authors reported that the bulk density and water stable aggregates decreased significantly while the evapotranspiration increased by $35 \%$ and $50 \%$ with with PA and PEST, respectively. The water holding capacity of the soil as well as the microbial metabolic activity increased increased with the introduction of MPs. The authors also showed that PEST and PS significantly increased the root biomass biomass compared with HDPE, PET and PP MPs [81].

Besides, PVC MPs of sizes less than $0.5 \mathrm{~mm}$ had an acute and chronic toxicity on the growth of garden cress (Lepidium sativum) [82, 83]. Furthermore, Hernández-Arenas et al. [84] studied the effect of sewage sludge containing MPs on the development of tomato plants in term of biomass and lenth for shoot and root, and the stem diameter and tomato production. Tomato plants (Lycopersicon esculentum Mill.) were cultivated in soil, manure, soil containing peat moss: silica sand: manure: sludge at a ratio of 50:50:0:0, 45:45:10:0, and 45:45:0:10. Each type of soil was replicated in seven pots and after3 and half months the tomatoes were harvested. The authors showed that the soil containing sewage sludge contaminated with MP delayed and diminished tomato production. However, the authors also highlighted that other factors such as heavy metal may have influenced the results [84].

The negative impacts of MPs in aquatic organisms have received much scientific attention in the past decades. Studies are now reporting that MPs can have a negative impact on the soil biodiversity and ecosystem functioning [85]. For instance, Chen et al. [86] highlighted the surface damage of Eisenia fetida earthworms at a concentration of $1.5 \mathrm{~g} / \mathrm{kg}$ of LDPE MPs $(<400 \mu \mathrm{m})$ and showed the presence of LDPE MPs $(<100 \mu \mathrm{m})$ in the earthworm's egestate. High accumulation of MPs in the soil ecosystems might have damaging effects on crop production as well as on the soil organisms [31, 87]. MPs particles can be ingested by biota and they bioaccumulate in the organisms whereby the organisms are physically distorted and bear internal abrasion and blockages [88, 89]. Ingested MPs have the propensity to sorb persistent organic pollutants, plastic additives and other toxic elements that are carcinogenic and deleterious to the endocrine system [15, 64, 90, 91].

\section{Microplastics pathways/fate in soils}

Once the MPs are deposited on the agricultural soil surfaces through various routes, they experience several pathways contributing to their propagation throughout the soil environment. Soil is porous which makes the migration of MPs particles possible. For instance, Grayling et al. [92] highlighted the movement of MPs particles of sizes $0.1-6.0 \mu \mathrm{m}$ in the soil column, while larger sizes we retained into the soil acting as a sink. Unfortunately, MPs can be transported into the nearby water bodies through wind and rainfall, and can also migrate into deeper soils through soil organisms which increases the chances of aquifers contamination [41]. For instance, Maßß et al. [93] tested whether soil microarthropods, Folsomia candida and Proisotoma minuta, can transport MP particles over large distances. Urea-formaldehyde particles (200-400 $\mu \mathrm{m}$ particle size) and polyethylene terephthalate fibres were ground into two particle fractions: $<100 \mu \mathrm{m}$ and 100-200 $\mu \mathrm{m}$. The study gave evidence of the movement and distribution of MPs by soil microarthropods.

Huerta-Lwanga et al. [94] assessed the effects of MPs and the amount of MPs that were transported and deposited in Lumbricus terrestris. The worms were exposed to the soil surface litter treatments containing LDPE for 2 weeks at different concentrations: $0 \%, 7 \%, 28 \%, 45 \%$ and $60 \%$. The results showed L. terrestris transported the MPs from the soil surface into their burrows in a size-selective way. This study also gave evidence of MPs uptake and biogenic transport into soil by worms may lead to the pollution of underground water, uptake by terrestrial plants as well as enter the terrestrial food webs. Another study showed an increased concentration of MPs in earthworm casts $\left(129.8 \pm 82.3\right.$ particles. $\left.^{-1}\right)$ and in chicken faeces (10.2 \pm 13.8 MPs particles per gizzard) with increasing MP concentration in home garden soil [95]. The authors also predicted that humans can accumulate $840 \mathrm{MP}$ particles/person/year through the consumption of chicken gizzards [95]. 


\section{Gaps in Research and future perspectives}

1. This review provides an insight into the different analytical methods used for the identification of MPs in different terrestrial environment. The most commonly used methodologies include random sampling, sieving followed by flotation method and identification using stereo microscope, SEM, FTIR and Raman spectroscopy. As stated earlier, there are no standardised protocols for the identification of MPs in the terrestrial environment.

2. Different authors devised their own methodological approach for the extraction and analysis of MPs which hinders the evaluation of MPs present in the soil environment. Additionally, there is little information on the agricultural practices of the farmers/ planters in terms of plastic usage and disposal.

3. Further research is needed for the distribution of MPs in soil through the use of treated wastewater for irrigation and compost.

4. The spatial and temporal planes have to be considered to provide a holistic picture for characterizing and quantifying MPs in different environmental conditions.

5. Characteristion and quantification of MPs are essential in order to gauge the degradation caused by plastics and take remedial actions. The use of chemical fertilisers is common practice in agricultural lands and these can either be absorbed or adsorbed by the MPs.

6. It is important to determine the effect of heavy metals that might be present in the chemical fertilisers on the MPs. It would also be interesting to determine the eco-toxicological impacts of MPs in the terrestrial environment.

7. Current literature focuses mainly on lands where there are direct input of MPs or plastics. This may not be very efficient to provide a holistic approach regarding MP pollution in the soil. Hence, further research still needs to be carried out in other types of land and regions. The sampling sites history is also beneficial for comparison.

8. The effects of MPs in agricultural soils have been demonstrated by recent studies posing a significant threat to the soil biota, plants and animals, ultimately the human health through food chain. Besides, the results of this study provide evidence of the fragmentation and disintegration of larger plastic particles into MPs which can reduce further into nanoplastics. Research on the impact of nanoplastics on soil biota and plants is still at its infancy due to its size and high cost associated. Hence, proper management of plastic wastes in agricultural lands together with regular cleaning is vital to reduce MP loads in the terrestrial environment.

\section{Acknowledgements}

The authors are grateful to the university for providing literature facilities. This research was funded by Higher Education Commission full-time Postgraduate Scholarship to D. Ragoobur. Funding: This work was supported by the Higher Education Commission [INT-2018-17].

Disclamer: Any opinion, findings and conclusions or recommendations expressed in this publication are those of the author(s) and do not necessarily reflect the views of the Higher Education Commission.

\section{References}

[1] PlasticsEurope, "Plastics-the Facts: An analysis of European plastics production, demand and waste data," Plastics Europe, Belgium, 2017.

[2] D. Barnes, F. Galgani, R. Thompson and M. Barlaz, "Accumulation and fragmentation of plastic debris in global environments," Philosophical Transactions of The Royal Society B, vol. 364, pp. 1985-1998, 2009.

[3] A. Horton, C. Svendsen, R. Williams, D. Spurgeon and E. Lahive, "Large microplastic particles in sediments of tributaries of the River Thames, UK - Abundance, sources and methods for effective quantification," Mar Pollut Bull., vol. 114, no. 1, pp. 218-226, 2017.

[4] D. He, Y. Luo, S. Lu, M. Liu, Y. Song and L. Lei, "Microplastics in soils: Analytical methods, pollution characteristics and ecological risks," TrAC - Trends Anal Chem, vol. 109, pp. 163-172, 2018.

[5] C. Crawford and B. Quinn, "Microplastics, standardization and spatial distribution," in Microplastic Pollutants, Elsevier, 2017, pp. 203-218.

[6] J. David, H. Weissmannnova, Z. Steinmetz, L. Kabelikova, M. Demyan, J. Simeckova, D. Tokarski, C. Siewert, G. Schaumann and J. Kucerik, "Introducing a soil universal model method (SUMM) and its application for qualitative and 
quantitative determination of poly(ethylene), poly(styrene), poly(vinyl chloride) and poly(ethylene terephthalate) microplastics in a model soil," Chemosphere, vol. 225, pp. 810-819, 2019.

[7] E. Carpenter and K. S. Jr, "Plastics on the Sargasso Sea Surface," Science, vol. 175, no. 4027, pp. 1240-1241, 1972.

[8] R. Thompson, Y. Olson, R. Mitchell, A. Davis, S. Rowland, A. John, D. McGonigle and A. Russell, "Lost at Sea: Where Is All the Plastic?," Science, vol. 304, no. 5672, p. 838, 2004.

[9] GESAMP, "Sources, Fate and Effects of Microplastics in the Marine Environment: Part Two of the a Global Assessment," International Maritime Organisation, London, 2016.

[10] H. Auta, C. Emenike and S. Fauziah, "Distribution and importance of microplastics in the marine environment A review of the sources, fate, effects, and potential solutions," Environ Int, vol. 102, pp. 165-176, 2017.

[11] J. Talvitie, A. Mikola, A. Koistinen and O. Setälä, "Solutions to microplastic pollution - Removal of microplastics from wastewater effluent with advanced wastewater treatment technologies," Water Res, vol. 123, pp. 401-407, 2017.

[12] F. Saliu, S. Montano, M. Garavaglia, M. Lasagni, D. Seveso and P. Galli, "Microplastic and charred microplastic in the Faafu Atoll, Maldives," Mar Pollut Bull, vol. 136, pp. 464-471, 2018.

[13] J. Prata, J. D. Costa, A. Duarte and T. Rocha-Santos, "Methods for sampling and detection of microplastics in water and sediment: A critical review," TrAC - Trends Anal Chem, vol. 110, pp. 150-159, 2019.

[14] M. Cole, H. Webb, P. Lindeque, P. Fileman, C. Halsband and T. Galloway, "Isolation of microplastics in biota-rich seawater samples and marine organisms," Sci. Rep., vol. 4, p. 4528, 2013.

[15] A. Andrady, "The plastic in microplastics: A review," Mar Pollut Bull, vol. 119, no. 1, pp. 12-22, 2017.

[16] A. Cincinelli, C. Scopetani, D. Chelazzi, C. Lombardini, T. Martellini, A. Katsoyiannis, M. Fossi and S. Corsolini, "Microplastic in the surface waters of the Ross Sea (Antarctica): Occurrence, distribution and characterization by FTIR," Chemosphere, vol. 175, pp. 391-400, 2017.

[17] A. Cincinelli, T. Martellini, C. Guerranti, C. Scopetani, D. Chelazzi and T. Giarrizzo, "A potpourri of microplastics in the sea surface and water column of the Mediterranean Sea," TrAC Trends Anal Chem, vol. 110, pp. 321-326, 2018.

[18] R. Dris, J. Gasperi, V. Rocher, M. Saad, N. Renault and B. Tassin, "Microplastic contamination in an urban area: a case study in Greater Paris," Environ. Chem, vol. 12, pp. 592-599, 2015.

[19] P. Anderson, S. Warrack, V. Langen, J. Challis, M. Hanson and M. Rennie, "Microplastic contamination in Lake Winnipeg, Canada," Environ Pollut, vol. 225, pp. 223-231, 2017.

[20] H. Bouwman, K. Minnaar, C. Bezuidenhout and C. Verster, "Microplastics in Freshwater Water Environments," Water Research Commission, South Africa, 2018.

[21] M. Di and J. Wang, "Microplastics in surface waters and sediments of the Three Gorges Reservoir, China," Sci. of the Environ., Vols. 616-617, pp. 1620-1627, 2018.

[22] N. Dikareva and K. Simon, "Microplastic pollution in streams spanning an urbanization gradient," Environ. Pollut., vol. 250, pp. 292-299, 2019.

[23] R. Vaughan, S. Turner and N. Rose, "Microplastics in the sediments of a UK urban lake," Environ. Pollut., vol. 229, pp. 10-18, 2017.

[24] W. Yuan, X. Liu, W. Wang, M. Di and J. Wang, "Microplastic abundance, distribution and composition in water, sediments, and wild fish from Poyang Lake, China," Ecotoxicol. Environ. Saf., vol. 170, pp. 180-187, 2019.

[25] C. Zhang, H. Zhou, Y. Cui, C. Wang, Y. Li and D. Zhang, "Microplastics in offshore sediment in the Yellow Sea and East China Sea, China," Environ. Pollut., vol. 244, pp. 827-833, 2019.

[26] M. Browne, P. Crump, S. Niven, E. Teuten and A. Tonkin, "Accumulation of microplastic on shorelines worldwide: sources and sinks," Environ. Sci. and Techol., vol. 45, no. 1, pp. 9175-9179, 2011.

[27] F. Corradini, H. Bartholomeus, E. Huerta-Lwanga, H. Gertsen and V. Geissen, "Predicting soil microplastic concentration using vis-NIR spectroscopy," Sci. Total Environ., vol. 650, pp. 922-932, 2019.

[28] X. Han, X. Lu and R. Vogt, "An optimized density-based approach for extracting microplastics from soil and sediment samples," Environ. Pollut., vol. 254, 2019.

[29] G. Zhang and Y. Liu, "The distribution of microplastics in soil aggregate fractions in southwestern China," Sci. Total Environ., vol. 642, pp. 12-20, 2018.

[30] F. Liu, G. Liu, Z. Zhu and F. Zhao, "Interactions between microplastics and phthalate esters as affected by microplastics characteristics and solution chemistry," Chemosphere, vol. 214, pp. 688-694, 2018. 
[31] Y. Chae and Y. An, "Current research trends on plastic pollution and ecological impacts on the soil ecosystem: A review," Environ. Pollut., vol. 240, pp. 387-395, 2018.

[32] R. Roychand and B. Pramanik, "Identification of micro-plastics in Australian road dust," J. Environ. Chem. Eng, vol. 8, no. 1, pp. 1-5, 2020.

[33] J. Wang, Y. Luo, Y. Teng, W. Ma, P. Christie and Z. Li, "Soil contamination by phthalate esters in Chinese intensive vegetable production systems with different modes of use of plastic film," Environ. Pollut., vol. 180, pp. 265-273, 2013.

[34] M. Scheurer and M. Bigalke, "Microplastics in Swiss Floodplain Soils," Environ. Sci Technol., vol. 52, no. 6, pp. 3591-3598, 2018.

[35] S. Zhang, X. Yang, H. Gertsen, P. Peters, T. Salanki and V. Geissen, "A simple method for the extraction and identification of light density microplastics from soil," Sci. Total Environ., Vols. 616-617, pp. 1056-1065, 2018.

[36] X. Liu, W. Yuan, M. Di, Z. Li and J. Wang, "Transfer and fate of microplastics during the conventional activated sludge process in one wastewater treatment plant of China," Chem. Eng, vol. 362, pp. 176-182, 2019.

[37] W. Lv, W. Zhou, S. Lu, W. Huang, Q. Yuan, M. Tian, W. Lv and D. He, "Microplastic pollution in rice-fish co-culture system: A report of three farmland stations in Shanghai, China," Sci. Total Environ., vol. 652, pp. 1209-1218, 2019.

[38] R. Qi, D. Jones, Z. Li, Q. Liu and C. Yan, "Behaviour of microplastics and plastic film residues in the soil environment: a critical review," Science of the Total Environment, p. 134722, 2020.

[39] J. Guo, X. Huang, L. Xiang, Y. Wang, Y. Li, H. Li, Q. Cai, C. Mo and M. Wong, "Source, migration and toxicology of microplastics in soil," Environment International, vol. 137, p. 105263, 2020.

[40] J. Li, Y. Song and Y. Cai, "Focus topics on microplastics in soil: analytical methods, occurence, transport, and ecological risks," Environmental Pollution, vol. 257, p. 113570, 2020.

[41] M. Kumar, X. Xiong, M. He, D. Tsang, J. Gupta, E. Khan, S. Harrad, D. Hou, Y. Ok and N. Bolan, "Microplastics as pollutants in agricultural soils," Environmental Pollution, vol. 265, p. 114980, 2020.

[42] E. Dümichen, A. Barthel, U. Braun, C. Bannick, K. Brand, M. Jekel and R. Senz, "Analysis of polyethylene microplastics in environmental samples, using a thermal decomposition method," Water Res., vol. 85, pp. 451-457, 2015.

[43] M. Rillig, "Microplastic in Terrestrial Ecosystems and the Soil?," Environ. Sci. Technol., vol. 46, pp. 6453-6454, 2012.

[44] C. Crawford and B. Quinn, "Microplastic collection techniques," in Microplastic Pollutants, Elsevier, 2017, pp. 179-

202.

[45] V. Hidalgo-Ruz, L. Gutow, R. Thompson and M. Thiel, "Microplastics in the Marine Environment: A Review of the Methods used for Identification and Quantification," Environ. Sci. Technol., vol. 46, pp. 3060-3075, 2012.

[46] M. Claessens, L. Van-Cauwenberghe, B. Michiel and C. Janssen, "New techniques for the detection of microplastics in sediments and field collected organisms," Mar. Pollut. Bull., vol. 70, pp. 227-233, 2013.

[47] J. Wang, J. Peng, Z. Tan, Y. Gao, Z. Zhan and Q. Chen, "Microplastics in the surface sediments from the Beijiang River littoral zone: Composition, abundance, surface textures and interaction with heavy metals," Chemosphere, vol. 171, pp. 248-258, 2017.

[48] M. Nuelle, J. Dekiff, D. Remy and E. Fries, "A new analytical approach for monitoring microplastics in marine sediments," Environ. Pollut., vol. 184, pp. 161-169, 2014.

[49] H. Imhof, R. Sigl, E. Brauer, S. Feyl, P. Giesemann, S. Klink, K. Leupolz, M. Löder, L. Löschel, J. Missun, S. Muszynski, A. Ramsperger, I. Schrank, S. Speck, S. Steibl, B. Trotter, I. Winter and C. Laforsch, "Spatial and temporal variation of macro-, meso- and microplastic abundance on a remote coral island of the Maldives, Indian Ocean," Mar. Pollut. Bull., vol. 116, pp. 340-347, 2017.

[50] P. V. d. Berg, E. Huerta-Lwanga, F. Corradini and V. Geissen, "Sewage sludge application as a vehicle for microplastics in eastern Spanish agricultural soils," Environ. Pollut., vol. 261, 2020.

[51] Q. Zhou, H. Zhang, C. Fu, Y. Zhou, Z. Dai, Y. Li, C. Tu and Y. Luo, "The distribution and morphology of microplastics in coastal soils adjacent to the Bohai Sea and the Yellow Sea," Geoderma, vol. 322, pp. 201-208, 2018.

[52] M. Liu, S. Lu, Y. Song, L. Lei, J. Hu, W. Lv, W. Zhou, C. Cao, H. Shi, X. Yang and D. He, "Microplastic and mesoplastic pollution in farmland soils in suburbs of Shanghai, China," Environ. Pollut., vol. 242, pp. 855-862, 2018.

[53] F. Corradini, P. Meza, R. Eguiluz, F. Casado, E. Huerta-Lwanga and V. Geissen, "Evidence of microplastic accumulation in agricultural soils from sewage," Sci. Total Environ., vol. 671, pp. 411-420, 2019. 
[54] M. Bläsing and W. Amelung, "Science of the Total Environment Plastics in soil : Analytical methods and possible sources," Sci. Total Environ., vol. 612, pp. 422-435, 2018.

[55] J. Jiang, "Occurrence of microplastics and its pollution in the environment: A review," Sustain. Prod. Consum., vol. 13, pp. 16-23, 2018.

[56] S. Fuller and A. Gautam, "A procedure for measuring microplastics using pressurized fluid extraction," Environ. Sci. Technol., vol. 50, no. 11, pp. 5774-5780, 2016.

[57] K. Zubris and B. Richards, "Synthetic fibers as an indicator of land application of sludge," Environ. Pollut., vol. 138, no. 2, pp. 201-211, 2005.

[58] J. Li, Y. Song and Y. Cai, "Focus topics on microplastics in soil: Analytical methods, occurrence, transport, and ecological risks," Environ. Pollut., vol. 257, 2020.

[59] J. Shan, J. Zhao, L. Liu, Y. Zhang, X. Wang and F. Wu, "A novel way to rapidly monitor microplastics in soil by hyperspectral imaging technology and chemometrics," Environ. Pollut., vol. 238, pp. 121-129, 2018.

[60] H. Liu, X. Yang, G. Liu, C. Liang, S. Xue, H. Chen, C. Ritsema and V. Geissen, "Response of soil dissolved organic matter to microplastic addition in Chinese loess soil," Chemosphere, vol. 185, pp. 907-917, 2017.

[61] C. Crawford and B. Quinn, "Microplastic separation techniques," in Microplastic Pollutants, Elsevier, 2017, pp. 203218.

[62] A. Mahon, B. O'Connell and M. Healy, "Microplastics in sewage sludge: Effects of treatment," Environ. Sci. Technol., vol. 51, no. 2, pp. 810-818, 2017.

[63] S. Felsing, C. Kochleus, S. Buchinger, N. Brennholt, F. Stock and G. Reifferscheid, "A new approach in separating microplastics from environmental samples based on their electrostatic behavior," Environ. Pollut., vol. 234, pp. 20-28, 2018. [64] A. Silva, A. Bastos, C. Justino, J. D. Costa, A. Duarte and T. Rocha-Santos, "Microplastics in the environment: Challenges in analytical chemistry - A review," Anal. Chim. Acta, vol. 1017, pp. 1-19, 2018.

[65] Q. Ruimin, D. Jones, L. Zhen, L. Qin and Y. Changrong, "Behavior of microplastics and plastic film residues in the soil environment: A critical review," Sci. Total Environ., vol. 703, 2020.

[66] Q. Qiu, Z. Tan, J. Wang, J. Peng, M. Li and Z. Zhan, "Extraction, enumeration and identification methods for monitoring microplastics in the environment," Estuar. Coast. Shelf. Sci., vol. 176, pp. 102-109, 2016.

[67] F. Stock, C. Kochleus, D. Bänsch-Baltruschat, N. Brennholt and G. Reifferscheid, "Sampling techniques and preparation methods for microplastic analyses in the aquatic environment - A review," TrAC - Trends Anal Chem, vol. 113, pp. 84-92, 2019.

[68] S. Mintenig, I. Int-Veen, M. Löder, S. Primpke and G. Gerdts, "Identification of microplastic in effluents of waste water treatment plants using focal plane array-based micro-Fourier-transform infrared imaging," Water Res., vol. 108, pp. 365-372, 2017.

[69] R. Hurley, A. Lusher, M. Olsen and L. Nizzetto, "Validation of a Method for Extracting Microplastics from Complex, Organic-Rich, Environmental Matrices," Environ. Sci. Technol., vol. 52, no. 13, pp. 7409-7417, 2018.

[70] M. Eriksen, S. Mason, S. Wilson, C. Box and A. Zellers, "Microplastics pollution in the surface waters of the Laurentian Great Lakes," Mar. Pollut. Bull., vol. 77, pp. 177-182, 2013.

[71] A. Massos and A. Turner, "Cadmium, lead and bromine in beached microplastics," Environ. Pollut., vol. 227, pp. 139145, 2017.

[72] P. Anger, E. Von-der-Esch, T. Baumann, M. Elsner, R. Niessner and N. Ivleva, "Raman microspectroscopy as a tool for microplastic particle analysis," TrAC - Trends Anal Chem, vol. 109, pp. 214-226, 2018.

[73] G. Renner, A. Nellessen, A. Schwiers, M. Wenzel, T. Schmidt and J. Schram, "Data Preprocessing \& Evaluation used in the Microplastics Identification Process: A Critical Review \& Practical Guide," TrAC - Trends Anal Chem, vol. 111, pp. 229-238, 2019.

[74] C. Araujo, M. Nolasco, A. Ribeiro and P. Ribeiro-Claro, "Identification of microplastics using Raman spectroscopy: Latest developments and future prospects," Water Res., vol. 142, pp. 426-440, 2018.

[75] K. Magnusson and F. Noren, "Screening of microplastic particles in and down-stream a wastewater treatment plant," 2014.

[76] P. Gandara-e-Silva, C. Nobre, P. Resaffe, C. Pereira and F. Gusmão, "Leachate from microplastics impairs larval development in brown mussels," Water Res., vol. 106, pp. 364-370, 2016. 
[77] M. Fischer and B. Scholz-Böttcher, "Simultaneous Trace Identification and Quantification of Common Types of Microplastics in Environmental Samples by Pyrolysis-Gas Chromatography-Mass Spectrometry," Environ. Sci. Technol., vol. 51, no. 9, pp. 5052-5060, 2017.

[78] S. Mintenig, P. Bäuerlein, A. Koelmans, S. Dekker and A. Van-Wezel, "Closing the gap between small and smaller: towards a framework to analyse nano- and microplastics in aqueous environmental samples," Environ. Sci. Nano, vol. 5, no. 7, pp. 1640-1649, 2018.

[79] E. Dümichen, P. Eisentraut, C. Bannick, A. Barthel, R. Senz and U. Braun, "Fast identification of microplastics in complex environmental samples by a thermal degradation method," Chemosphere, vol. 174, pp. 572-584, 2017.

[80] M. Liu, Y. Song, S. Lu, R. Qiu, J. Hu, X. Li, M. Bigalke, H. Shi and D. He, "A method for extracting soil microplastics through circulation of sodium bromide solutions," Sci. Total Environ., vol. 691, pp. 341-347, 2019.

[81] A. de Souza Machado, C. Lau, W. Kloas, J. Bergmann, J. Bachelier, E. Faltin, R. Becker, A. Gorlich and M. Rillig, "Microplastics can change soil properties and affect plant performance," Environmental Science and Technology, vol. 53, pp. 6044-6052, 2019.

[82] S. Pignattelli, A. Broccoli and M. Renzi, "Physiological responses of garden cress (L. sativum) to different types of microplastics," Science of the Total Environment, vol. 727, p. 138609, 2020.

[83] T. Bosker, L. Bouwman, N. Brun, P. Behrens and M. Vijver, "Microplastics accumulate on pores in seed capsule and delay germination and root growth of the terrestrial vascular plant Lepidium sativum," Chemosphere, vol. 226, pp. 774-781, 2019.

[84] R. Hernández-Arenas, A. Beltrán-Sanahuja, P. Navarro-Quitant and C. Sanz-Lazaro, "The effect of sewage sludge containing microplastics on growth and fruit development of tomato plants," Environmental Pollution, vol. 268, no. B, p. $115779,2021$.

[85] B. Boots, C. Russell and D. Green, "Effects of microplastics in soil ecosystems: Above and below ground," Environmental Science \& Technology, vol. 53, no. 19, pp. 11496-11506, 2019.

[86] Y. Chen, X. Liu, Y. Leng and J. Wang, "Defense responses in earthworms (Eisenia fetida) exposed to low-density polyethylene microplastics in soils," Ecotoxicology and Environmental Safety, vol. 187, p. 109788, 2020.

[87] E. Ng, E. Huerta-Lwanga, S. Eldridge, P. Johnston, H. Hu, V. Geissen and D. Chen, "An overview of microplastic and nanoplastic pollution in agroecosystems," Sci. Total Environ., vol. 627, pp. 1377-1388, 2018.

[88] S. Wright, D. Rowe, R. Thompson and T. Galloway, "Microplastic ingestion decreases energy reserves in marine worms," Current Biology, vol. 23, no. 23, pp. R1031-1033, 2013.

[89] N. Laskar and U. Kumar, "Plastics and microplastics: A threat to environment," Environmental Technology \& Innovation, vol. 14, p. 100352, 2019.

[90] S. Coffin, S. Dudley, A. Taylor, D. Wolf, J. Wang, I. Lee and D. Schenk, "Comparisons of analytical chemistry and biological activities of extracts from Noth Pacific gyre plastics with UV-treated plastics using in vitro and in vivo models," Environ. Int., vol. 121, pp. 942-954, 2018.

[91] E. Teuten, J. Saquing, D. Knappe, M. Barlaz, S. Jonsson, A. Björn, S. Rowland, R. Thompson, T. Galloway, R. Yamashita, D. Ochi, Y. Watanuki, C. Moore, P. Viet, S. Tana, M. Prudente, R. Boonyatumanond, M. Zakaria, K. Akkhavong and Ogata, "Transport and release of chemicals from plastics to the environment and to wildlife," Philos. T. R. Soc. B, vol. 364, pp. 2027-2045, 2009.

[92] K. Grayling, S. Young, C. Roberts, M. de Heer, I. Shirley, C. Sturrock and S. Mooney, "The application of X-ray micro computed tomography imaging for tracing particle movement in soil," Geoderma, vol. 321, pp. 8-14, 2018.

[93] S. Maaß, D. Daphi, A. Lehmann and M. Rillig, "Transport of microplastics by two collembolan species," Environmental Pollution, vol. 225, pp. 456-459, 2017.

[94] E. Huerta Lwanga, H. Gertsen, H. Gooren, P. Peters, T. Salanki, M. van der Ploeg, E. Besseling, A. Koelmans and G. Violette, "Incorporation of microplastics from litter into burrows of Lumbricus terrestris," Environmental Pollution, vol. 220, pp. 523-531, 2017.

[95] E. Huerta-Lwanga, H. Gertsen, H. Gooren, P. Peters, T. Salanki, M. V. d. Ploeg, E. Besseling, A. Koelmans and G. Violette, "Incorporation of microplastics from litter into burrows of Lumbricus terrestris," Environ. Pollut., vol. 220, pp. 523-531, 2017. 